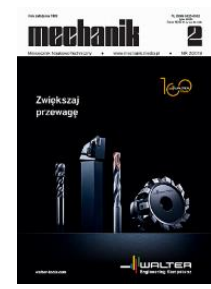

How to cite this article:

Authors: Andrzej Nowakowski, Piotr Putyra, Tadeusz Krzywda

Title of article: "Electrodischarge machining of silicon nitride composites and silicon carbide composites"

Mechanik, No. 2 (2019)

DOI: https://doi.org/10.17814/mechanik.2019.2.19

\title{
Electrodischarge machining of silicon nitride composites and silicon carbide composites
}

\author{
ANDRZEJ NOWAKOWSKI \\ PIOTR PUTYRA \\ TADEUSZ KRZYWDA*
}

Dr inż. Andrzej Nowakowski, andrzej.nowakowski@ios.krakow.pl - Instytut Zaawansowanych Technologii Wytwarzania, Polska Dr inż. Piotr Putyra, piotr.putyra@ios.krakow.pl - Instytut Zaawansowanych Technologii Wytwarzania, Polska

inż. Tadeusz Krzywda, tadeusz.krzywda@ios.krakow.pl - Instytut Zaawansowanych Technologii Wytwarzania, Polska

The paper presents the results of physical and mechanical properties of the and $\mathrm{Si}_{3} \mathrm{~N}_{4}$ and $\mathrm{SiC}$ matrix ceramics with additives of good electrical conductivity carbides, nitrides and borides phases. The density, Young's modulus, hardness HV1 and electrical conductivity of each material were investigated. Ceramic composite materials with the participation of the conductive phases have been produced using SPS (spark plasma sintering) method. Materials characterized by good electrical conductivity were shaped using EDM (electro discharge machining) method.

KEYWORDS: ceramics materials, SPS sintering, electro discharge machining

\section{Introduction}

Ceramic materials are characterized by many favorable mechanical properties (high hardness and strength in a wide temperature range, resistance to oxidizing and corrosive environments - also at high temperature, as well as resistance to thermal shocks). Ceramic elements are manufactured by uniaxial pressing, densification and sintering. Forming of ceramic parts having more complicated shapes can be carried out with the use of electro discharge machining, if the workpiece has adequate electrical conductivity. The introduction of natural conductors - $\mathrm{TiN}, \mathrm{TiC}, \mathrm{Ti}(\mathrm{C}, \mathrm{N})$ or $\mathrm{TiB}_{2}$ into the matrix - improves the conductivity of multi-phase ceramics and allows it to be made of very geometrically complicated elements using electro discharge machining.

The paper presents possibilities of electro discharge shaping of ceramic composites based on silicon nitride and silicon carbide. Stable, long-lasting drilling of these composites was possible in conditions of negative polarization of the working electrode and a duty cycle of 0.5 .

In the case of a composite with $\mathrm{Si}_{3} \mathrm{~N}_{4}$ matrix with the addition of high resistance $\mathrm{TiB}_{2}$, it was necessary to introduce structural changes in the pulse current generator and the regulator of the gap between the electrodes and increase the voltage supplying the generator's working circuit to $480 \mathrm{~V}$. Drilling composites with silicon nitride and silicon carbide matrix with low resistance, and the addition of $\mathrm{TiC}, \mathrm{TiN}$ and $\mathrm{TiB}_{2}$, took place with an ignition circuit voltage of $200 \mathrm{~V}$ and parameter settings corresponding to medium accurate and finishing machining. The tests were carried out on the EDEF-40 experimental EDM drilling machine with the UZSDf-40 generator, designed and made at the Research Network Lukasiewicz Krakow Institute of Technology.

\section{Materials}

Ceramic composites based on $\mathrm{Si}_{3} \mathrm{~N}_{4}$ and $\mathrm{SiC}$, with the addition of phases with good electrical conductivity in the form of $\mathrm{TiB}_{2}$, $\mathrm{TiC}$ and TiN were produced. Powder mixes were prepared with the following compositions (the content of powders in the mixtures is expressed in $\%$ by volume):

- $\mathrm{Si}_{3} \mathrm{~N}_{4}+30 \% \mathrm{TiB}_{2}+3.4 \% \mathrm{ZrO}_{2}+1.9 \% \mathrm{MgO}+1.7 \% \mathrm{Al}_{2} \mathrm{O}_{3}$,

- $\mathrm{Si}_{3} \mathrm{~N}_{4}+50 \% \mathrm{TiN}+5 \% \mathrm{Al}_{2} \mathrm{O}_{3}+3 \% \mathrm{Y}_{2} \mathrm{O}_{3}$,

- $\mathrm{Si}_{3} \mathrm{~N}_{4}+50 \% \mathrm{TiC}+5 \% \mathrm{Al}_{2} \mathrm{O}_{3}+3 \% \mathrm{Y}_{2} \mathrm{O}_{3}$,

- $\mathrm{SiC}+30 \% \mathrm{TiB}_{2}$. 
Additives in the form of oxide phases $\left(\mathrm{Al}_{2} \mathrm{O}_{3}, \mathrm{MgO}\right.$ and $\left.\mathrm{ZrO}_{2}\right)$ were also used for composites based on silicon nitride, which were aimed at improving sinterability. Individual mixtures were prepared in a high energy Pulverisette 6 planetary mill, with the particle size of the batch powders not exceeding $3 \mu \mathrm{m}$. Mixtures based on $\mathrm{Si}_{3} \mathrm{~N}_{4}$ and $\mathrm{SiC}$ with the addition of ceramic conductive phases were also ground in a Pulverisette 6 mill, using a bowl and balls made of $\mathrm{Si}_{3} \mathrm{~N}_{4}$ and with the addition of isopropanol. The rotational speed of the mill was $200 \mathrm{rpm}$ and the milling time was $60 \mathrm{~min}$. After drying, the mix was granulated using a $0.9 \mathrm{~mm}$ sieve.

Materials to be sintered using the SPS device were pre-pressed in a graphite matrix at a pressure of $30 \mathrm{MPa}$. The applied sintering parameters for individual materials are presented in tab. I.

TABLE I. Parameters of the material sintering process using the FCT-HP D 5 device

\begin{tabular}{|c|c|c|c|c|}
\hline Composition & Force, $\mathbf{k N}$ & Temperature, ${ }^{\circ} \mathbf{C}$ & Time, $\mathbf{m i n}$. & Protective atmosphere \\
\hline $\mathrm{Si}_{3} \mathrm{~N}_{4}+\mathrm{TiB}_{2}$ & 100 & 1550 & 10 & nitrogen \\
\hline $\mathrm{Si}_{3} \mathrm{~N}_{4}+\mathrm{TiC}$ & 100 & 1550 & 10 & argon \\
\hline $\mathrm{Si}_{3} \mathrm{~N}_{4}+\mathrm{TiN}$ & 100 & 1550 & 10 & argon \\
\hline $\mathrm{SiC}_{+} \mathrm{TiB}_{2}$ & 25 & $1800 \div 2000$ & 5 & argon \\
\hline
\end{tabular}

Apparent density $\rho p$ was measured by hydrostatic method. Hardness was determined by the Vickers method at $980.7 \mathrm{mN}$ load, using the Future Tech Corp FM-7 digital hardness tester. The surface for these tests was prepared using the ACUTOM cutter-grinder from Struers. The Young's modulus of sintered samples was also measured by ultrasonic method of measuring the transverse and longitudinal wave velocity - the Panametrics Epoch III detector was used. The microstructural analysis of the materials was carried out by scanning electron microscopy, using the SEM scanning electron microscope JSM-6460LV. Chemical composition in micro-areas was also analyzed using EDS INCA X-act Energy 350 X-ray spectrometers and WDS INCA Wave from Oxford Instruments. Physical and mechanical properties (density, Young's modulus, HV1 hardness, electrical conductivity) of individual materials after sintering are summarized in tab. II.

TABLE II. Physical and mechanical properties of $\mathrm{Si}_{3} \mathbf{N}_{4}$ materials after sintering SPS

\begin{tabular}{|c|c|c|c|c|}
\hline Composition & Density, $\mathbf{g} / \mathbf{c m}^{3}$ & Young's modulus, GPa & Hardness HV1 & Resistance, $\Omega$ \\
\hline $\mathrm{Si}_{3} \mathrm{~N}_{4}+\mathrm{TiB}_{2}$ & 3.51 & 318 & 1918 & 500 \\
\hline $\mathrm{Si}_{3} \mathrm{~N}_{4}+\mathrm{TiC}$ & $3.22 \div 3.38$ & - & - & 0.1 \\
\hline $\mathrm{Si}_{3} \mathrm{~N}_{4}+\mathrm{TiN}$ & $3.96 \div 4.02$ & 290 & 1032 & 0.1 \\
\hline $\mathrm{SiC}+\mathrm{TiB}_{2}$ & $3.16 \div 3.51$ & $321 \div 419$ & $1590 \div 2350$ & 0.3 \\
\hline
\end{tabular}

\section{Drilling composite with high resistance}

The attempt to process the $\mathrm{Si}_{3} \mathrm{~N}_{4}+\mathrm{TiB}_{2}$ composite on the drilling machine in the normal generator operation system was unsuccessful, because due to the high resistivity of this material, (about $500 \Omega$ ) the operating current was too low. Also, the inter-electrode gap thickness regulator, working on the principle of stabilizing the average inter-electrode voltage, did not work properly, because an unfavorable voltage resistance divider was formed in the operating current circuit, in which the proportion of inter-electrode voltage subjected to stabilization was only a few percent. For the purpose of drilling this composite, the generator's working current circuit was redesigned and the algorithm for stabilizing the thickness of the electrode gap was changed. As a result of these changes, it was possible for the generator to work at the voltage supplying the working current circuit. set in the range from $160 \mathrm{~V}$ to $600 \mathrm{~V}$. To control the working electrode feed. a regulator was used, which instead of the average inter-electrode voltage, stabilized the average value of the working current. The block diagram of the drill during drilling of a high-resistance composite is shown in fig. 1. 


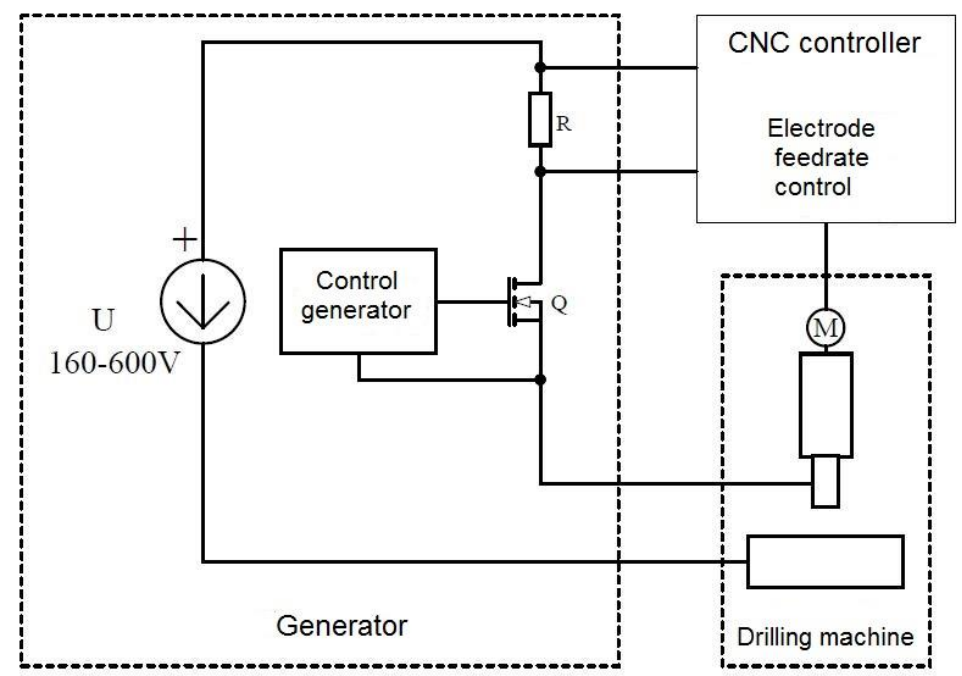

Fig. 1. Block diagram of the drilling machine control circuits for drilling high-resistance $\mathrm{Si}_{3} \mathrm{~N}_{4}+\mathrm{TiB}_{2}$ composite

Long-term stable drilling was obtained at a voltage supplying the working circuit of $480 \mathrm{~V}$. Further increase of this voltage led to arcing. In turn, at lower voltage, the discharges disappeared due to the formation of semiconductive bridges. The working current amplitude reached about $1.5 \mathrm{~A}$, and the average value of the current - $0.3 \mathrm{~A}$. The obtained machining efficiency, on the order of $0.8 \mathrm{mg} / \mathrm{min}$, was much lower than when drilling similar materials with low resistance. The relative wear of the working electrode was about $20 \%$.

The surface of the $\mathrm{Si}_{3} \mathrm{~N}_{4}+\mathrm{TiB}_{2}$ material after electro discharge drilling was subjected to microstructure analysis and chemical composition analysis using scanning electron microscopy. The distribution of elements on the surface (fig. 2) and chemical composition in micro-areas (fig. 3. tab. III) were examined.

As a result of the electro discharge drilling of the $\mathrm{Si}_{3} \mathrm{~N}_{4}+\mathrm{TiB}_{2}$ material, the phase composition on the machined surface changed. Analysis of the microstructure and chemical composition revealed the presence of phases at the boundaries of grains abundant in titanium and zirconium. It should be added, that in the process of preparing the mixture, among others $\mathrm{ZrO}_{2}$ and $\mathrm{TiB}_{2}$ powders were applied. As a result of electro-discharge machining the oxide phase is reduced and the boron phase is broken down. It is likely that a $\mathrm{B}_{2} \mathrm{O}_{3}$ phase is formed with a melting point of approximately $450{ }^{\circ} \mathrm{C}$ and evaporation around $1860{ }^{\circ} \mathrm{C}$. The Ti-Zr phase diagram (fig. 4) shows that these elements are characterized by unlimited solubility and can form a solution with a low melting point (approximately $1500{ }^{\circ} \mathrm{C}$ ), lower than the melting point of pure elements. The $\mathrm{Ti}-\mathrm{Zr}$ solution separated at the grain boundaries is clearly visible in figs. 2 and 3 (Spectrum 1. 2. 4 and 6). The boron phase decomposition and zirconia reduction can be the result of arcing and high temperature generation. The formation of a Ti-Zr solution with a low melting point can. in turn, be the reason for the formation of semiconductive bridges and the disappearance of discharges.

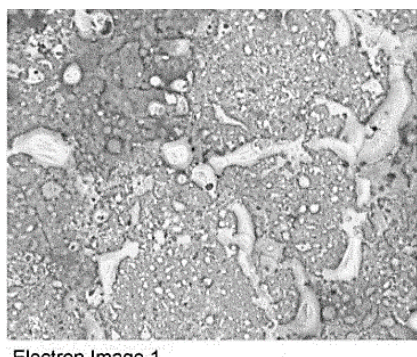

Electron Image 1

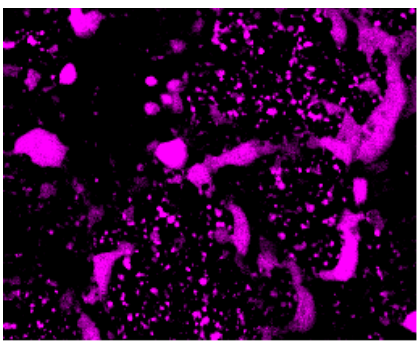

Ti Ka1

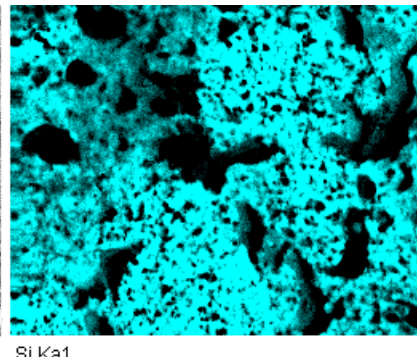

Si Ka1

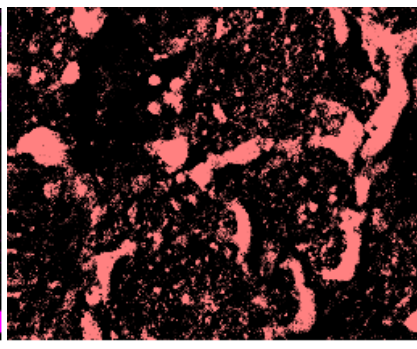

Zr La1 

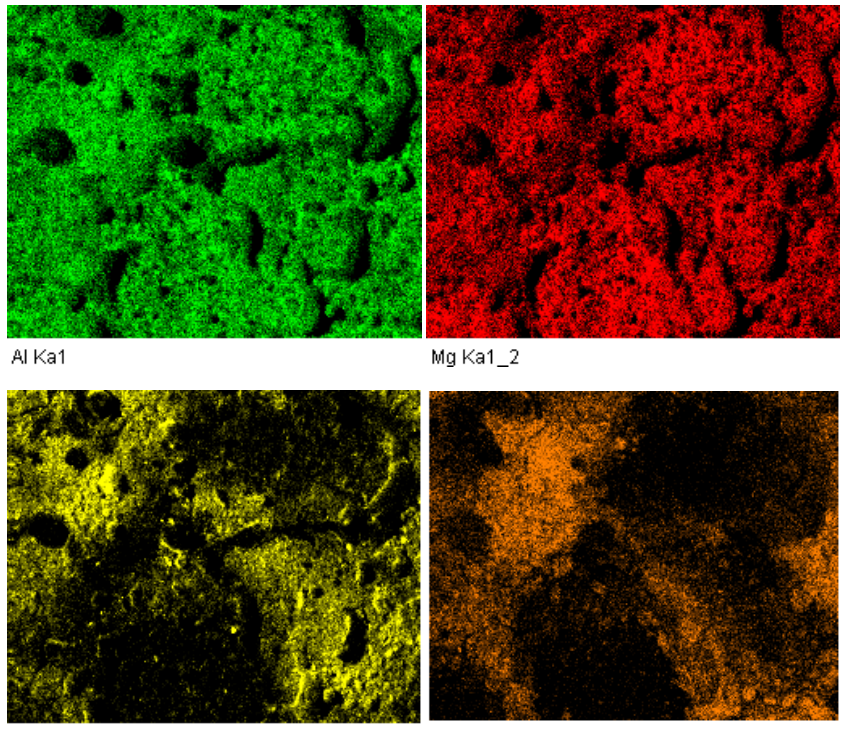

Mg Ka1_2

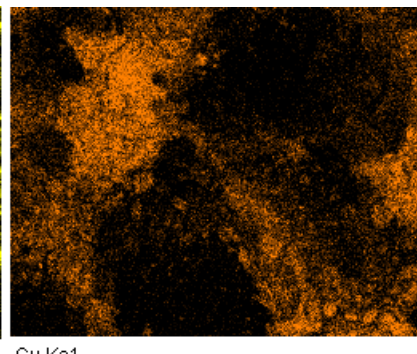

CuKa1

Fig. 2. Distribution of elements on the surface of the $\mathrm{Si}_{3} \mathrm{~N}_{4}+\mathrm{TiB}_{2}$ material after electro discharge drilling

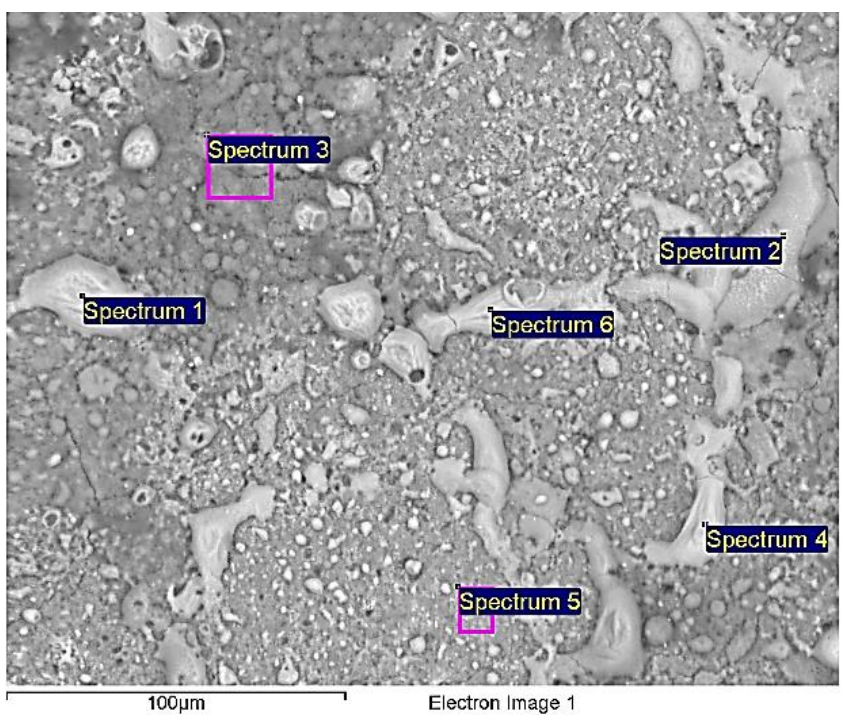

Fig. 3. Microstructure on the surface of the $\mathrm{Si}_{3} \mathrm{~N}_{4}+\mathrm{TiB}_{2}$ material after electro discharge drilling and analysis of chemical composition in micro-areas

TABLE III. Results of chemical composition analysis in micro-areas on the surface of $\mathrm{Si}_{3} \mathrm{~N}_{4}+\mathrm{TiB}_{2}$ material after electro discharge drilling

\begin{tabular}{|c|c|c|c|c|c|c|c|c|c|}
\hline Spectrum & $\mathrm{C}$ & $\mathrm{N}$ & $\mathrm{O}$ & $\mathrm{Mg}$ & $\mathrm{Al}$ & $\mathrm{Si}$ & $\mathrm{Ti}$ & $\mathrm{Cu}$ & $\mathrm{Zr}$ \\
\hline Spectrum 1 & 29.6 & & & & 0.2 & 25.1 & 36.5 & 0.8 & 7.8 \\
\hline Spectrum 2 & 21.7 & & & & 0.2 & 37.2 & 31.9 & 0.9 & 8.1 \\
\hline Spectrum 3 & 41.1 & & 14.0 & 0.5 & 1.0 & 30.8 & 5.9 & 5.5 & 1.3 \\
\hline Spectrum 4 & 21.9 & & & & & 24.8 & 41.8 & 0.7 & 10.7 \\
\hline Spectrum 5 & 9.9 & 23.4 & 3.1 & 0.6 & 0.8 & 48.7 & 10.8 & 0.3 & 2.4 \\
\hline Spectrum 6 & 28.1 & & & & & 29.8 & 32.8 & 1.5 & 7.8 \\
\hline
\end{tabular}




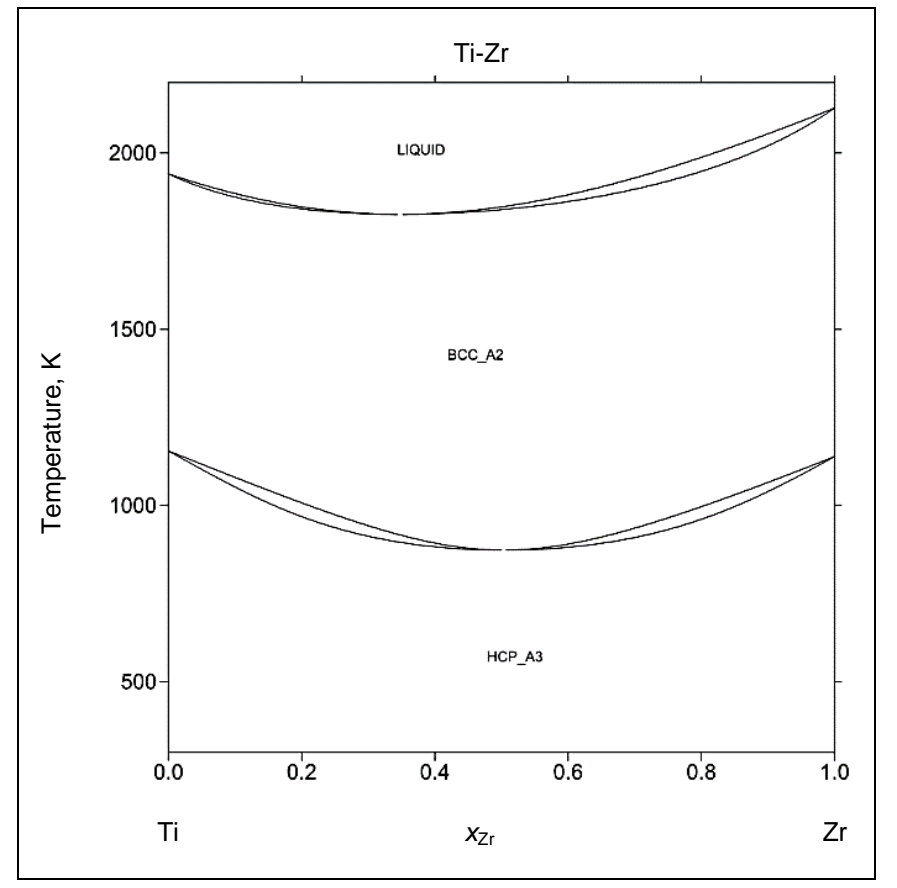

Fig. 4. Phase diagram of the two-component Ti-Zr system

\section{Drilling composites with low resistance}

Electro discharge drilling tests of five composites based on silicon nitride and silicon carbide $-\mathrm{Si}_{3} \mathrm{~N}_{4}+\mathrm{TiN}_{\text {, }}$ $\mathrm{Si}_{3} \mathrm{~N}_{4}+\mathrm{TiC}, \mathrm{SiC}+\mathrm{TiB}_{2}$ - with resistance ranging from $0.5 \Omega$ to $3 \Omega$ were carried out. No major technical difficulties were encountered during their processing.

The drilling took place with a negative polarization of the working electrode and a duty cycle of 0.5 . In most cases, it was beneficial to increase the ignition circuit voltage to $200 \mathrm{~V}$. The drilling was performed with parameter settings corresponding to medium accurate and finishing machining.

Finishing requires a low pulse energy setting, which can be achieved with a low operating current amplitude and longer pulse duration, or with a higher operating current amplitude and short pulse duration. Studies have confirmed that it is better to set a higher working current amplitude $(7 \mathrm{~A})$ and short pulses $(10$ $\mu \mathrm{s}$ and $6 \mu \mathrm{s}$ ) in the field of finishing treatment. Although in both settings variants a similar roughness of the machined surface was obtained ( $R a$ below 1.8 ), however in the first case the drilling efficiency was much higher. An example of a roughness profile is shown in fig. 5.

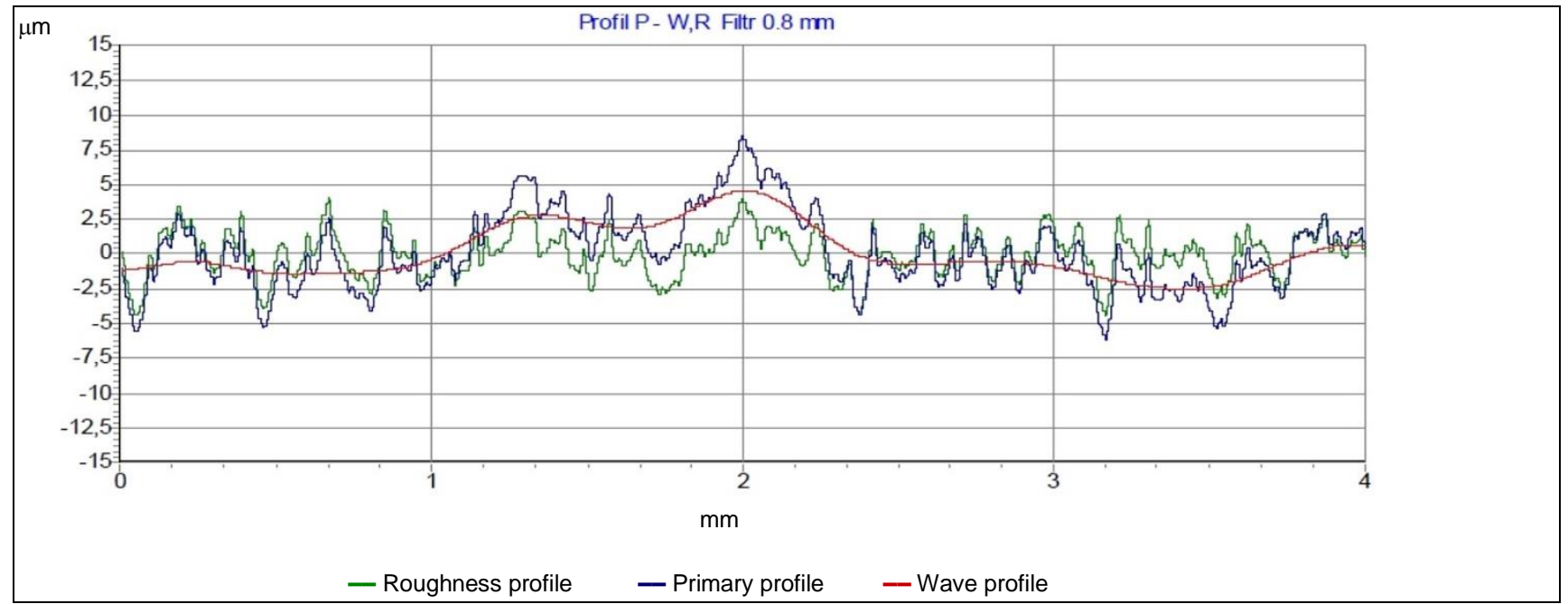

Fig. 5. $\mathrm{Si}_{3} \mathrm{~N}_{4}+$ TiN composite roughness profile. $\mathrm{Ra}=1.2$ (generator

settings: $I r=7$ A. $T i=6 \mu s . ~ T o=6 \mu s$ ) 


\section{Conclusions}

- Drilling the super-hard ceramic composites on a silicon nitride matrix, characterized by high resistance, is possible after constructional changes in the working current pulse generator. However, then the machining efficiency is very low.

- The generator ignition voltage is an important parameter. In most cases, the drilling process proceeded best with an ignition voltage of approximately $200 \mathrm{~V}$.

- Finishing of composites based on silicon nitride should be carried out with such intensity of working current pulses as during medium-precise machining and with setting the pulse time from a few to several microseconds.

- Discharges during electrical discharge machining can lead to a change in the phase composition of the $\mathrm{Si}_{3} \mathrm{~N}_{4}$ matrix with the addition of the $\mathrm{TiB}_{2}$ conductive phase.

The boron phase decomposition and zirconium oxide reduction occur as well as the formation of a lowmelting titanium and zirconium solution. The formation of the liquid phase can lead to bridging and disappearance of discharges. therefore there is a need for electrode oscillation.

The research material was produced as part of the SINTERCER project (project No. 316232. Development of a SINTERing CEntRe and know-how exchange for non-equilibrium sintering methods of advanced ceramic composite materials. REGPOT-2012-2013-1 EU FP7 Research Potential).

Electro discharge shaping tests were carried out as part of the statutory activity of the Institute of Advanced Manufacturing Technologies. 